\title{
Time Series Analysis of Monthly Generated Revenue in Gombe Local Government
}

\author{
Okorie Charity Ebelechukwu', Ossai Faith Chioma ${ }^{2}$, Ben Johnson ${ }^{3}$ \\ ${ }^{1,2,3}$ Department of Mathematics and Statistics, Federal University, Wukari, Taraba State, Nigeria
}

*Corresponding Author: Okorie Charity Ebelechukwu, Department of Mathematics and Statistics, Federal University, Wukari, Taraba State, Nigeria

\begin{abstract}
This study focuses on the generation of revenues in Gombe Local Government and the yearly increase or decrease in revenue generation over the years. The aim is to develop a pattern in the management of revenue generation and to see if there is a steady increase in the revenue generated over the years. The data used in this work is a secondary data, collected from the inland revenue department of the Local Government. The data covered period of eleven years, from 2006 to 2016. Analysis were carried out using the ordinary Least square and Autoregressive Moving Average (ARMA) models. The results from the two methods (That is, the linear trend and the moving average) show a steady increase in the revenue generated over the years and a slight instability in the deseasonalised data.
\end{abstract}

Keywords: Revenue, forecasting, moving average, trend, generated, analysis.

\section{INTRODUCTION}

Gombe is a state in north-eastern Nigeria, it was created out of Bauchi State on 1st October 1996 by the late General Sanni Abacha's Administration with its capital at Gombe. The State has Gombe as one of the Local Government Area. The capacity of local government to generate revenue internally is one very crucial consideration for the creation of a local council. Local government plays a crucial role in the delivery of services to the citizenry. The success of any local government is its ability to utilize its human and material resources to achieve the desired objectives i.e. rendering needed services to the community. Local government is a government in which popular participation both in the choice of decision makers and in its recognition of a third tier of government. Prior to 1976, however, Nigerian local government has passed through various reforms and organization. These reforms and reorganizations have affected the system financially, administratively, politically and functionally. Revenue generation in Nigeria Local Government is principally derived from Tax. Meanwhile tax is a compulsory levy imposed by Government on individuals and companies for the various legitimate function of the State (Olaoye, 2008). According to Ocheni et al., (2013) the statutory allocation from the federation account, serving as the main source of revenue to local government, is said to be inadequate and untimely received by the local government administration to enable discharge their obligations. Adenugba and Chike (2013) define revenue sources as the funds required by the government to finance its activities. These funds are generated from different sources such as taxes, borrowing, fines, fees and statutory etc. Therefore, revenue sources are the total amount of income that accrues to organization (public or private) within a specific period of time. Ibrahim (2011) defines local government as the breaking down of government functions, into smaller units for the purpose of administration established by law. The smaller units of government are concern to play direct part through the elected representative, who exercises authority and functions under supervision of the central government. According to Maduako (2010) the functions of local government have two fold purposes for its existence created to render services in defined geographical areas. Majorly, the existence of local government was due to inability of the central government to meet the rural needs in satisfying government 17 institutions. However, the first function is administrative, concerned with welfare of the citizen in the provision of goods and services such as; street cleaning, sanitation, refuse collection, road construction and maintenance, housing, water and sewerage, primary education, clinics among others. Other function is to represent and involve citizens in determining specific public needs and how the needs can be met through elected or selected representatives. According to 
Ayapere (2013) the financial management of local government revenue is an essential part of public administration; to ensure accountability and efficiency in the provision of public goods and services. Ovaga (2012) the pattern of local governments "e sources of revenue in Nigeria is classified into two; internal and external sources of revenue generation. The Internally Generated Revenue (IGR) the sources through which local governments generate revenue through their own efforts in the course of discharging their constitutional responsibility. While External sources comprised of statutory allocation from the Federation Account, Grant-in-aid from the state government and loans from other financial institutions. Obinna Adubisi and Charity E. Okorie (2016), used autoregressive moving average to model the growth pattern of currency in Nigeria.

\section{Statement of the Problem}

Source of finance has been one of the major problems of Local Governments in Nigeria. Some of the problems are Failure to remit 10\% to Local Government by State Governments, the embezzlement of revenue by Local Government revenue collectors, misplacement of council funds by Local Government chairmen . Based on the above stated problems, it has become necessary to conduct an analysis on internally generated revenue in Gombe Local Government.

\section{Aim}

The aim of this research work is to develop a pattern in the management of revenue generated using time series analysis.

\section{Objectives}

i. To show the pattern of revenue collection over the period (2006 - 2016)

ii. To study the general charges of the monthly revenue using time series.

iii. To forecast the future revenue collection of Gombe local government.

\section{Materials AND Methods}

\subsection{Time Series Models}

Time series models is a dynamic research area which has attracted attentions of researchers' community over last few decades. The main aim of time series modeling is to carefully collect and rigorously study the past observations of a time series to develop an appropriate model which describes the inherent structure of the series. This model is then used to generate future values for the series, i.e. to make forecasts. Time series forecasting thus can be termed as the act of predicting the future by understanding the past. The two methods of Time series applied in this work are;

\subsubsection{The Ordinary Least Square Method(OLS)}

Linear Least Square Regression is a method of fitting an affine line to set of data points. This method is used throughout many disciplines including statistic, engineering, and science. The method of least square is used to obtain unique trend line. The trend line is represented by the general equation of the straight line which is given by: $Y=a+b x$, where ' $b$ ' is the slope and ' $a$ ' is the intercept of $y$-axis.

The least square method used in the requirement that the sum of squares of deviations of the $y$ values corresponding to the value of regression must be minimum as $\mathrm{Y}=\mathrm{a}+\mathrm{bx}+\mathrm{e}$, where $\mathrm{Y}$ is dependent variable, $\mathrm{X}$ is independent variable, and $\mathrm{a}$ and $\mathrm{b}$ is the population parameter that gives the $\mathrm{Y}$ interception and slope respectively and $\mathrm{e}$ is the error associated.

$\mathrm{Y}=\mathrm{a}+\mathrm{bx}+\mathrm{e}$

$\mathrm{Y}=\mathrm{y}-\mathrm{y}_{1}$, where $\mathrm{y}_{1}=\mathrm{a}+\mathrm{bx}$

Let $\sum e=\sum\left(y-y_{1}\right)$

$\sum \mathrm{e}=\sum(\mathrm{y}-\mathrm{a}-\mathrm{bx})$

Square both sides; $\sum \mathrm{e}^{2}=\sum(\mathrm{y}-\mathrm{a}-\mathrm{bx})^{2}$

Differentiate both sides partially with respect to a 
$\frac{d}{d a}\left(\sum e\right)=\frac{d}{d a} \sum(y-a-b x)^{2}$

$0=-2 \sum(y-a-b x)$

Dividing both sides by 2

$0=\sum(y-a-b x)$

$0=\sum y-n a-b \sum x$

na $=\sum y-b \sum x$

Dividing both sides by $\mathrm{n}$

$a=\bar{y}-b \bar{x}$

Now differentiating with respect to $b$

$$
\begin{aligned}
& \frac{d}{d b} \sum e^{2}=\frac{d}{d b} \sum(y-a-b x)^{2} \\
& 0=2 x \sum(y-a-b x) \\
& \quad=\sum x y-a \sum x-b \sum x^{2}
\end{aligned}
$$

Substitute for value of $a=y-b x$

$$
\begin{aligned}
& \sum x y-(y-b x) \sum x-b \sum x^{2} \\
& \sum x y-y \sum x-b x \sum x-b \sum x^{2} \\
& b\left(\sum x^{2}-\frac{\left.\sum x \sum x\right)}{n}\right)=\frac{\sum x y-\sum x \sum y}{n} \\
& b=\frac{\sum x y-\frac{\sum y \sum x}{n}}{\sum x^{2}-\frac{\left(\sum x\right)^{2}}{n}} \\
& b=\frac{n \sum x y-\sum y \sum x}{n \sum x^{2}-\left(\sum x\right)^{2}}
\end{aligned}
$$

Hence, the required equation or the trend line equation is:

$\mathrm{Y}=\mathrm{a}+\mathrm{bx}$

Where $\mathrm{b}=\frac{\sum x y-\frac{\left(\sum x\right)\left(\sum y\right)}{n}}{\sum x^{2}-\frac{\left(\sum x\right)^{2}}{n}}$ 
$a=y-b x$

Where $\mathrm{y}=\frac{\sum y}{n}$

$$
\mathrm{X}=\frac{\sum x}{n}
$$

\subsubsection{The Autoregressive Moving Average (ARMA) Models}

An ARMA $(p, q)$ model is a combination of Autoregressive $(\operatorname{AR}(p))$ and Moving average $(\operatorname{MA}(q))$ models and is suitable for univariate time series modeling. In an $\operatorname{AR}(p)$ model the future value of a variable is assumed to be a linear combination of $p$ past observations and a random error together $Y_{t}$ ${ }_{=} \mathrm{c}+\sum \phi_{\mathrm{t}} \mathrm{y}_{\mathrm{t}-1}+\varepsilon_{\mathrm{t}}=\mathrm{c}+\phi_{1} \mathrm{y}_{\mathrm{t}-1}+\phi_{2} \mathrm{y}_{\mathrm{t}-2}+\ldots \ldots+\phi_{\mathrm{p}} \mathrm{y}_{\mathrm{t}-\mathrm{p}}+\varepsilon_{\mathrm{t}} \quad(13)$

Here $t y$ and $t \varepsilon$ are respectively the actual value and random error (or random shock) at time period $t$, $(i 1,2, . ., p) i \phi=$ are model parameters and $c$ is a constant. The integer constant $p$ is known as the order of the model. Sometimes the constant term is omitted for simplicity.

\section{RESUlTS}

The tables below show the results of the analysis carried out with the two methods stated above.

\subsection{The Least Square Analysis}

Table 1. Presentation Of Result And Analysis From The Data Used

\begin{tabular}{|c|c|c|c|c|c|c|}
\hline Year & month & $\mathrm{x}$ & $\mathrm{y}$ & Fits S1 & RESI1 & AVER1 \\
\hline 2006 & January & 1 & 129823 & 179546 & -49723 & $*$ \\
\hline 2006 & February & 2 & 111023 & 193779 & -82756 & $*$ \\
\hline 2006 & March & 3 & 111414 & 208012 & -96598 & 331695 \\
\hline 2006 & April & 4 & 979622 & 222246 & 757376 & 434331 \\
\hline $\begin{array}{l}\cdot \\
\dot{\bullet} \\
\dot{\bullet} \\
\dot{\bullet} \\
\cdot\end{array}$ & $\begin{array}{l}\cdot \\
\cdot \\
\cdot \\
\cdot \\
\cdot \\
\cdot \\
\cdot\end{array}$ & $\begin{array}{l}\cdot \\
\cdot \\
\dot{ } \\
\cdot \\
\dot{ } \\
\cdot\end{array}$ & $\begin{array}{l}\bullet \\
\bullet \\
\bullet \\
\bullet \\
\bullet \\
\bullet \\
\bullet\end{array}$ & $\begin{array}{l}\cdot \\
\cdot \\
\cdot \\
\cdot \\
\cdot \\
\cdot \\
\cdot\end{array}$ & $\begin{array}{l}\cdot \\
\cdot \\
\cdot \\
\cdot \\
\cdot \\
\cdot \\
\cdot\end{array}$ & $\begin{array}{l}\cdot \\
\cdot \\
\cdot \\
\cdot \\
\cdot \\
\cdot \\
\cdot\end{array}$ \\
\hline 2016 & October & 130 & 2015632 & 2015632 & 0 & 2015632 \\
\hline 2016 & November & 131 & 2029865 & 2029865 & -0 & 2026307 \\
\hline 2016 & December & 132 & 2044098 & 2044098 & -0 & 2033423 \\
\hline & & & $*$ & 2058332 & $*$ & 2040540 \\
\hline & & & $*$ & 2072565 & $*$ & 2044098 \\
\hline & & & $*$ & 2086798 & $*$ & $*$ \\
\hline & & & $*$ & 2101031 & $*$ & $*$ \\
\hline
\end{tabular}




\subsection{Trend Analysis}

Data y

Length 136

Missing 4

Fitted Trend Equation

$\mathrm{Yt}=165313+14233 *_{\mathrm{t}}$

Accuracy Measures

MAPE $1.56370 \mathrm{E}+01$

MAD 8.82432E+04

MSD 3.13428E+10

Table 2. Trend Analysis

\begin{tabular}{|l|l|l|l|}
\hline Time & y & Trend & Detrended \\
\hline 1 & 129823 & 179546 & -49723 \\
\hline 2 & 111023 & 193779 & -82756 \\
\hline 3 & 111414 & 208012 & -96598 \\
\hline 4 & 979622 & 222246 & 757376 \\
\hline$\cdot$ & $\cdot$ & $\cdot$ & $\cdot$ \\
$\cdot$ & $\cdot$ & $\cdot$ & $\cdot$ \\
$\cdot$ & $\cdot$ & $\cdot$ & $\cdot$ \\
$\cdot$ & $\cdot$ & $\cdot$ & $\cdot$ \\
$\cdot$ & $\cdot$ & $\cdot$ & $\cdot$ \\
& $\cdot$ & $\cdot$ & $\cdot$ \\
\hline 130 & $\cdot$ & 2015632 & 0 \\
\hline 131 & 2015632 & 2029865 & -0 \\
\hline 132 & 2029865 & 2044098 & -0 \\
\hline 133 & 2044098 & 2058332 & $*$ \\
\hline 134 & $*$ & 2072565 & $*$ \\
\hline 135 & $*$ & 2086798 & $*$ \\
\hline 136 & $*$ & 2101031 & $*$ \\
\hline
\end{tabular}

\subsection{Forecasting}

Forecasts

Period Forecast: This covers a period of two years, starting from January 2017 to December, 2018.

Table 3 forecast for 2017 and 2018

$\begin{array}{ll}137 & 2115264 \\ 138 & 2129498 \\ 139 & 2143731 \\ 140 & 2157964 \\ 141 & 2172197 \\ 142 & 2186431 \\ 143 & 2200664 \\ 144 & 2214897 \\ 145 & 2229130 \\ 146 & 2243363 \\ 147 & 2257597 \\ 148 & 2271830 \\ 149 & 2286063\end{array}$




\begin{tabular}{ll}
\hline 150 & 2300296 \\
151 & 2314530 \\
152 & 2328763 \\
153 & 2342996 \\
154 & 2357229 \\
155 & 2371462 \\
156 & 2385696 \\
157 & 2399929 \\
158 & 2414162 \\
159 & 2428395 \\
160 & 2442629
\end{tabular}

Trend Analysis Plot for y

Linear Trend Model

$\mathrm{Yt}=165313+14233 * \mathrm{t}$
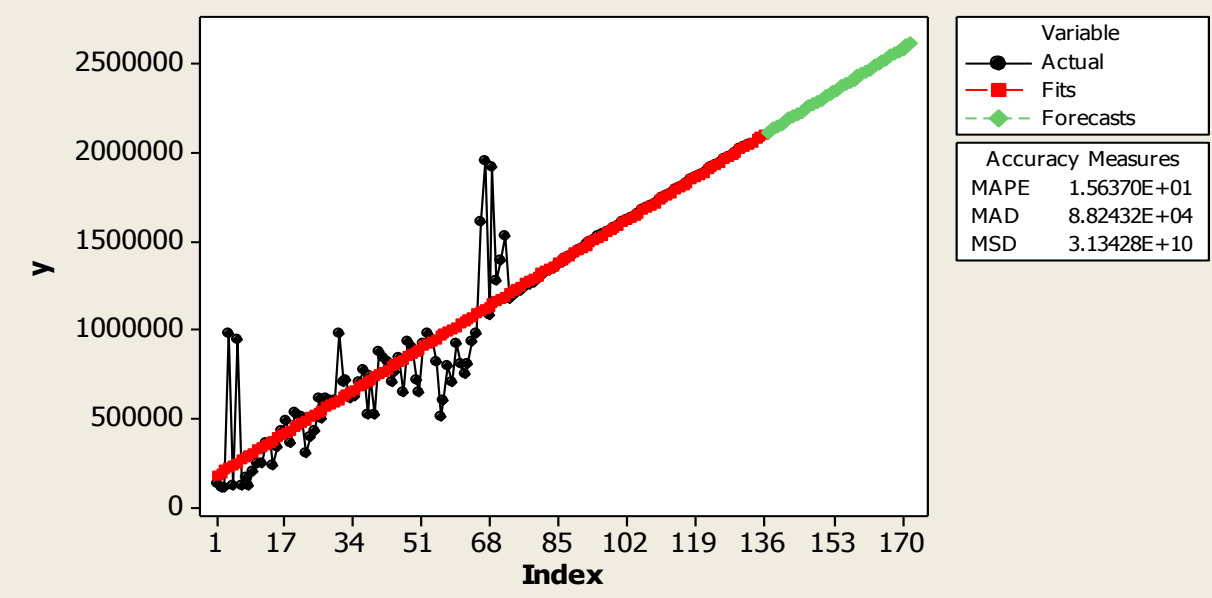

Figure 1. TREND ANALYSIS PLOT FOR Y.

\subsection{Moving Average}

\section{Moving Average for $\mathbf{y}$}

Data y

Length 136

Missing 4

Moving Average

Length 4

Accuracy Measures

MAPE 1.37495E+01

MAD 7.34701E+04

MSD 1.70779E+10

Table 4. Moving average

\begin{tabular}{|l|l|l|l|l|}
\hline Time & y & MA & Predict & Error \\
\hline 1 & 129823 & $*$ & $*$ & $*$ \\
\hline 2 & 111023 & $*$ & $*$ & $*$ \\
\hline 3 & 111414 & 331695 & $*$ & $*$ \\
\hline 4 & 979622 & 434331 & 331695 & 647927 \\
\hline. &. &. &. &. \\
\hline
\end{tabular}




\begin{tabular}{|l|l|l|l|l|}
\hline \hline$\cdot$ & $\cdot$ & $\cdot$ & $\cdot$ & $\cdot$ \\
$\cdot$ & $\cdot$ & $\cdot$ & $\cdot$ & $\cdot$ \\
$\cdot$ & $\cdot$ & $\cdot$ & $\cdot$ & $\cdot$ \\
$\cdot$ & $\cdot$ & $\cdot$ & $\cdot$ & $\cdot$ \\
\hline 130 & $\cdot$ & $\cdot$ & $\cdot$ & $\cdot$ \\
\hline 131 & 2015632 & 2015632 & 2001399 & 14233 \\
\hline 132 & 2029865 & 2026307 & 2015632 & 14233 \\
\hline 133 & 2044098 & 2033423 & 2026307 & 17791 \\
\hline 134 & $*$ & 2040540 & 2033423 & $*$ \\
\hline 135 & $*$ & 2044098 & 2040540 & $*$ \\
\hline 136 & $*$ & $*$ & 2044098 & $*$ \\
\hline
\end{tabular}

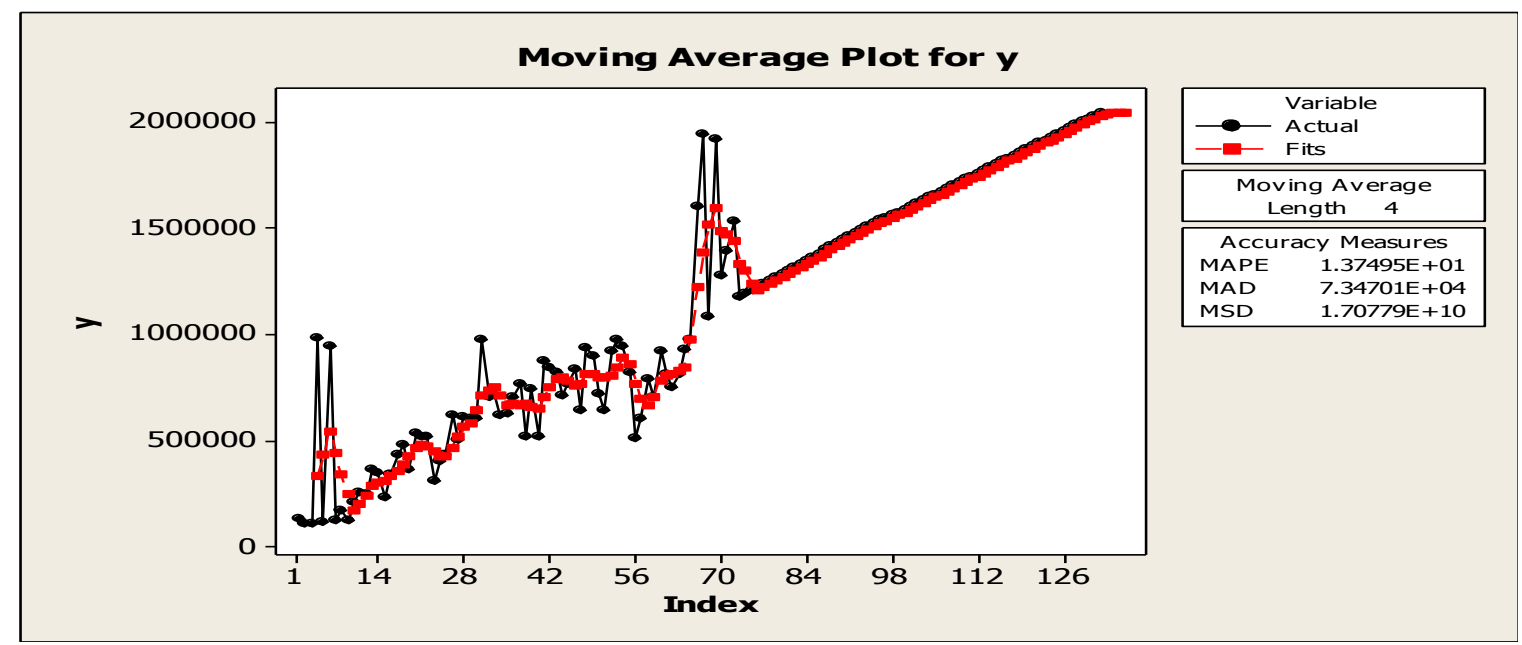

Figure 2. MOVING AVERAGE FOR PLOT Y

\section{DISCUSSION}

Looking at the results in table 1 and 2, the trend line is constructed by the use of least squares method shows a steady increase in the revenue collected over the period of eleven years (I.e. 2006 - 2016). The trend which was calculated using the least squares function $\mathrm{Y}=\mathrm{a}+\mathrm{bx}$, where $\mathrm{x}$ is same as the time function $t, Y=165313+14233 t$ shows a steady rise of revenue by 14233 . However, the slope of the least square equation indicates an upward movement of the Local Government Revenue.

Table 3, using the least square function $Y=165313+14233$ t, the forecast for the year 2017 to 2018 shows a steady increase in the monthly generated revenue.

Figure1 and figure 2, show a steady upward increase in the revenue generation overtime.

Table 4, the moving average of the whole eleven years indicates a steady increase in the revenue over these periods. There is a slight difference in the amount of revenue predicted and the observed (i.e. received revenue). In some instance the amount of Revenue predicted is higher than that of the observed. But due to the seasonal variation associated with the collection of revenue in some months, the data is deseasonalised by using a moving average of 12 months and a 4 point moving average.

\section{CONClusion}

Local government is the most familiar and universal form of democratic decentralization, endowed with its own power, finances and staff operating within the country, under the laws establishing it in the constitution (Muhammad 2012). The existence of local government was due to inability of the central government to meet the needs of the rural dwellers and so the Revenue of the Local government areas needs to be on the check. This is because, no local Government can operate without availability of Revenue.

\section{RECOMMENDATION}

The local government should try and get more ways of improving revenue, they should utilize their resources properly, clear and objective legal means should also be enacted to deal with tax defaulters. 


\section{REFERENCES}

[1] Adenugba A.A and Chike F.O.(2013),The Effect of Internally revenue generation on Infrastructural development, study of Lagos State Internal Revenue. Journal Educational and Social Reasearch 3(2) 6

[2] Ayapere P.(2013), The Impact of public financial management on local government administration(National Open university, Bayelsa),pp251

[3] Ibrahim F.A (2011), An assessment of the sources of revenue generation and its impact in local government; A study of some selected local governments in Niger State. (Unpublished Masters thesis), Ahmadu Bello university, Zaria, pp15.

[4] Maduako E.J.I(2010,The impact of poor revenue generation on development of local government areas; study of Umuahia North local government.(Published Masters thesis,Caritas University, Amorji-Nike Enugu),pp18.

[5] Ndan J.D.(2013),Public financial management: A Nigerian perspective, Zaria Saad-deen press limited, pp 43

[6] Obinna Adubisi and Charity E. Okorie(2016); MODELING THE GROWTH PATTERN OF RESERVE CURRENCY IN NIGERIA, FUW Trends in Science \& Technology Journal ftstjournal@gmail.com April, 2016 Vol. 1 No. 1 - e-ISSN: 24085162; p-ISSN: 20485170 pp 130-133

[7] Ocheni S., Atakpa M. and Nwankwo B.C.(2013); Analysis of the polities of local government budgeting in Nigeria (1995-2011), Academic journal of interdisciplinary studies, MCSER_CEMAS Saplenza University of Rome, vol2,pp 24

[8] Olaoye C.O.(2008); Concepts of taxation in Nigeria, Celement publishing, Ijagbo/Ofa, Kwara State

[9] Ovaga O.H.(2012); Funding in Local government system as a strategy for sustainable Rural development

[10]Zhang G.P,'Time Series forecasting using a highbred ARIMA and network model",Neurocomputing 50 (2003),pages 159-175..

Citation: O. C. Ebelechukwu et al., "Time Series Analysis of Monthly Generated Revenue in Gombe Local Government ", International Journal of Scientific and Innovative Mathematical Research, vol. 6, no. 2, p. 1724, 2018., http://dx.doi.org/10.20431/2347-3142.0602002

Copyright: () 2018 Authors. This is an open-access article distributed under the terms of the Creative Commons Attribution License, which permits unrestricted use, distribution, and reproduction in any medium, provided the original author and source are credited. 